\title{
Age-adjusted Reference Values and Z-scores of the Coronary Sinus Diameter among Healthy Children and Adolescents in Southern Iran
}

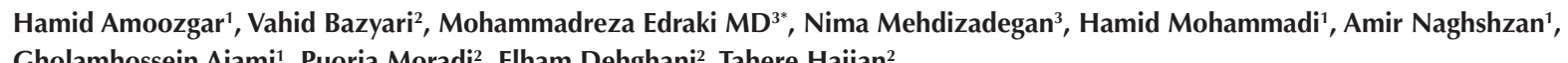
Gholamhossein Ajami ${ }^{1}$, Puoria Moradi², Elham Dehghani², Tahere Hajian²

${ }^{1}$ Neonatal Research Center, Shiraz University of Medical Sciences, Shiraz, Iran

${ }^{2}$ Pediatric Department, Shiraz University of Medical Sciences, Shiraz, Iran

${ }^{3}$ Cardiovascular Research Center, Shiraz University of Medical Sciences, Shiraz, Iran

\begin{abstract}
Background: Coronary sinus dimension is an important factor for diagnosing some types of cyanosis as well as congenital heart diseases and insertion of some devices into the coronary sinus if required. This study was designed to access the diameter and Z-score of the coronary sinus among children under 18 years of age.

Methods: In this cross-sectional study on 95 individuals, the coronary sinus diameter was measured by transthoracic echocardiography in the four-chamber view at the connection to the right atrium, middle part, and distal end. The linear regression equation was utilized to determine age-adjust reference values, Z-scores, and the relationship between the individuals' coronary sinus diameter age, height, and body surface area. The study was conducted from March to July 2020 in Namazi hospital clinic of Shiraz University of Medical Sciences, Shiraz, Iran.

Results: The mean age of the persons who entered this study was $5.87 \pm 4.25$ years. The mean coronary sinus diameter was $4.91 \pm 1.29 \mathrm{~mm}$ at the site of connection to the right atrium, $4.50 \pm 1.44 \mathrm{~mm}$ at the middle part, and $3.74 \pm 1.32 \mathrm{~mm}$ at the distal end. Coronary sinus diameter correlates positively with the participants' age, weight, height, and body surface area $(P<0.001)$. Conclusion: Coronary sinus diameter significantly correlates with the age, height, and body surface area of the cases. These features are useful in diagnosing some congenital heart diseases and insertion of suitable devices through it.

Keywords: Coronary sinus, Child, Echocardiography, Z-score

Cite this article as: Amoozgar H, Bazyari V, Edraki M, Mehdizadegan N, Mohammadi H, Naghshzan A, et al. Age-adjusted reference values and z-scores of the coronary sinus diameter among healthy children and adolescents in southern iran. Arch Iran Med. 2021;24(11):804-810. doi: 10.34172/aim.2021.120
\end{abstract}

Received: August 30, 2020, Accepted: January 10, 2021, ePublished: November 1, 2021

\section{Introduction}

The coronary sinus (CS) is the heart's main venous drainage, and the greater cardiac vein and the main posterolateral vein form the CS. ${ }^{1,2}$ Other major veins that enter CS are the inferior left ventricular vein and the middle cardiac vein that collect the posterior part of the left ventricle. In adults, CS is a muscular tube, 2 to $3 \mathrm{~cm}$ in length and $1 \mathrm{~cm}$ in diameter, located about $1 \mathrm{~cm}$ above and parallel to the junction of the left atrium and ventricle. ${ }^{1,3}$ Thebesian valve is a fold of endocardial tissue that forms the orifice of CS and is a remnant of the right embryonic sinoatrial junction valve. ${ }^{4}$

Knowledge about the CS anatomy is essential due to its importance in different heart procedures such as percutaneous mitral annuloplasty, retrograde cardioplegia, and biventricular pacing. Furthermore, it is important for deployment of various cardiac devices, ablation of arrhythmias, targeted drug delivery, stem cell therapy, and cardiac surgery. ${ }^{5,6}$

CS diameter correlates with right atrium size, and pulmonary artery systolic pressure. ${ }^{7}$ Dilation of CS can result from various conditions such as tricuspid stenosis, tricuspid regurgitation, right ventricular dysfunction, and pulmonary hypertension. ${ }^{8}$ Dilation of CS can stretch the atrioventricular node or His bundle and cause arrhythmias. $^{2,9}$

Today, there are many methods for assessing CS size, such as electrocardiography-gated multi-slice spiral computed tomography, cardiac magnetic resonance imaging, and echocardiography. ${ }^{10} \mathrm{~A}$ previous study measured the CS size using M-mode echocardiography, ${ }^{11}$ and another study measured the dimension in one segment of CS using 2-dimensional echocardiography. ${ }^{12}$

This study aims to determine CS size and show the normal reference value in children and adolescents by transthoracic echocardiography because this method is used in the daily practice of pediatric cardiologists.

\section{Materials and Methods}

In this cross-sectional study, we investigated healthy individuals under 18 years of age with weight and height between the 5th and 95th percentiles for age from March to July 2020 in the Namazi clinic of Shiraz University of Medical Sciences, Shiraz, Iran. All cases with abnormal 
physical exam, congenital heart diseases, pulmonary hypertension, persistent left superior vena cava, abnormal electrocardiography and growth failure were excluded. Age, weight, height, and gender of the individuals were recorded, and the linear regression equation $(\mathrm{Y}=\mathrm{a}+\mathrm{bx})$ was calculated for each parameter.

The transthoracic echocardiography machine was Samsung (Madison Co., Ltd. Samsung, HS70A, Korea) with 2-4 and 3-5 MHS transducer. The CS diameters were measured in the four-chamber view, from the end of diastole in maximum dimension, while the probe was showing the long axis of CS.

The superior and inferior diameters of CS were measured in the maximum dimension in three places (D1, D2, D3), while D1 was the diameter of CS $5 \mathrm{~mm}$ from the junction of the right atrium, D2 was the diameter of the middle part of CS and D3 was the diameter of the end part of CS (Figure 1).

An experienced pediatric cardiologist performed all measurements; the measuring of each diameter was done three times, and mean values were calculated to decrease inter-observatory variability.

The evaluation of inter-observer or intra class correlation coefficient was done in 10 patients to measure the CS diameters by two pediatric cardiologists, which showed excellent agreement in measurement of the three CS diameters.

Power analysis was done to determine the sample size, which was at least 90 subjects. A total of 117 subjects were enrolled; CS could not be evaluated well in 12 cases who were omitted from the study and finally, 95 patients were

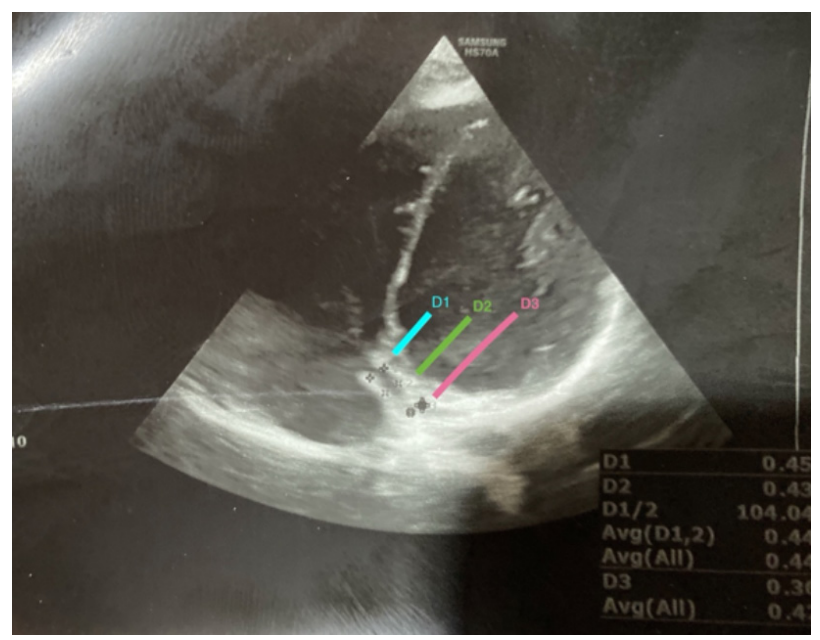

Figure 1. Coronary Sinus in 4-Chamber view. included.

\section{Statistical Analysis}

Data was analyzed using the IBM SPSS Statistics for Windows, version 20, using descriptive statistics $($ mean $\pm \mathrm{SD})$. Linear regression analysis between the CS diameter and age, weight, and body surface area was carried out. The Kolmogorov-Smirnov test was performed to assess normality. A $P$ value of less than 0.05 was considered as statistically significant.

\section{Results}

A total of 95 individuals were recruited for this study, as shown in Table 1. The mean CS diameter was $4.91 \pm 1.29$ $\mathrm{mm}$ at $\mathrm{D} 1,4.50 \pm 1.44 \mathrm{~mm}$ at $\mathrm{D} 2$, and $3.74 \pm 1.32 \mathrm{~mm}$ at D3. The Kolmogorov-Smirnov test for assessing normality of three CS diameters showed normal distribution of the data (D1: $\mathrm{D}(95)=0.07, P=0.2 ; \mathrm{D} 2: \mathrm{D}(95)=0.081, P=0.12$; D3: $\mathrm{D}(95)=0.063, P=0.08)$.

The intra class correlation coefficient was obtained to measure the CS diameters by two pediatric cardiologists, which showed good agreement in measurements of D1, D2 and D3 (Table 2).

The CS diameter was significantly correlated with age in all three cross-sections $(P<0.001)$ and can be calculated using the following linear regression equations:

$\mathrm{D} 1(\mathrm{~mm})=(3.901+0.187)$. Age (years $)(P<0.001, \mathrm{r}=0.61)$ $\mathrm{D} 2(\mathrm{~mm})=(3.362+0.205)$. Age (years $)(P<0.001, \mathrm{r}=0.67)$ D3 $(\mathrm{mm})=(2.739+0.187)$. Age (years $)(P<0.001, \mathrm{r}=0.63)$

The CS diameter was also significantly correlated with height in all cross-sections $(P<0.001)$ and can be calculated using the following formula:

$\mathrm{D} 1(\mathrm{~mm})=(2.478+0.023)$. height $(\mathrm{cm})(P<0.001, \mathrm{r}=0.59)$

$\mathrm{D} 2(\mathrm{~mm})=(1.899+0.024)$. height $(\mathrm{cm})(P<0.001, \mathrm{r}=0.63)$

$\mathrm{D} 3(\mathrm{~mm})=(1.516+0.021)$. height $(\mathrm{cm})(P<0.001, \mathrm{r}=0.55)$

Also, the correlation between body surface area and D1, D2, and D3 was investigated and calculated with the following formula:

Table 2. Strength of the Inter and Intra-observer Analysis for Each Echocardiographic Data

\begin{tabular}{lcc}
\hline Characteristics & Inter-observer ICC & Intra-observer ICC \\
\hline D1 & 0.79 & 0.94 \\
D2 & 0.75 & 0.93 \\
D3 & 0.65 & 0.86 \\
\hline
\end{tabular}

$\mathrm{D} 1$, the diameter of CS $5 \mathrm{~mm}$ from the junction of the right atrium; D2, the diameter of the middle part of CS; D3, the diameter of the end part of CS; ICC, intraclass correlation coefficient.

Table 1. Demographic Data of the Participants

\begin{tabular}{lcccc}
\hline Age Group & Number (\%) & $\begin{array}{c}\text { Age }(\mathbf{Y}) \\
\text { Mean } \pm \text { SD }\end{array}$ & $\begin{array}{c}\text { Weight (kg) } \\
\text { Mean } \pm \text { SD }\end{array}$ & $\begin{array}{c}\text { Height (cm) } \\
\text { Mean } \pm \text { SD }\end{array}$ \\
\hline$<1$ & $13(14.71)$ & $0.43 \pm 0.23$ & $5.81 \pm 2.30$ & $74.20 \pm 15.25$ \\
$\geq 1-5$ & $30(33.73)$ & $2.96 \pm 1.21$ & $14.7 \pm 45.61$ & $100.66 \pm 21.35$ \\
$\geq 5-10$ & $36(34.56)$ & $7.1 \pm 1.50$ & $24.83 \pm 7.93$ & $123.14 \pm 13.56$ \\
$\geq 10-18$ & $16(17.22)$ & $12.96 \pm 2.38$ & $44.80 \pm 10.44$ & $157.06 \pm 11.46$ \\
\hline
\end{tabular}


D1 $(\mathrm{mm})=(3.577+3.070)$. body surface area $(\mathrm{m} 2)$

$(P<0.001, \mathrm{r}=0.54)$

D2 $(\mathrm{mm})=(3.032+3.303)$. body surface area $(\mathrm{m} 2)$

$(P<0.001, \mathrm{r}=0.59)$

D3 $(\mathrm{mm})=(2.404+3.096)$. body surface area $(\mathrm{m} 2)$

$(P<0.001, \mathrm{r}=0.55)$

Figures 2-7 illustrate the linear regression between age, height, body surface area and the three CS diameters and also Z-scores of D1, D2, and D3. The bottom and top red lines in these figures show $5 \%$ and $95 \%$ of the data, respectively.

The linear regression chart was drawn for regression between age and the three CS diameters (Figure 2).

The linear regression chart was also drawn for regression between height and the three CS diameters (Figure 3).

Besides, the linear regression chart was drawn for regression between body surface area and the three CS diameters (Figure 4).

Also, linear regression between age, height, body surface area and Z-scores of D1, D2, and D3 was obtained and illustrated in Figures 5, 6, and 7, respectively.

\section{Discussion}

This study measured the CS diameters and their Z-scores in three CS parts among children and adolescents in southern Iran, using transthoracic echocardiography. The linear regression between the age, height, body surface and D1, D2, D3 and the Z-scores of the three CS diameters was determined.

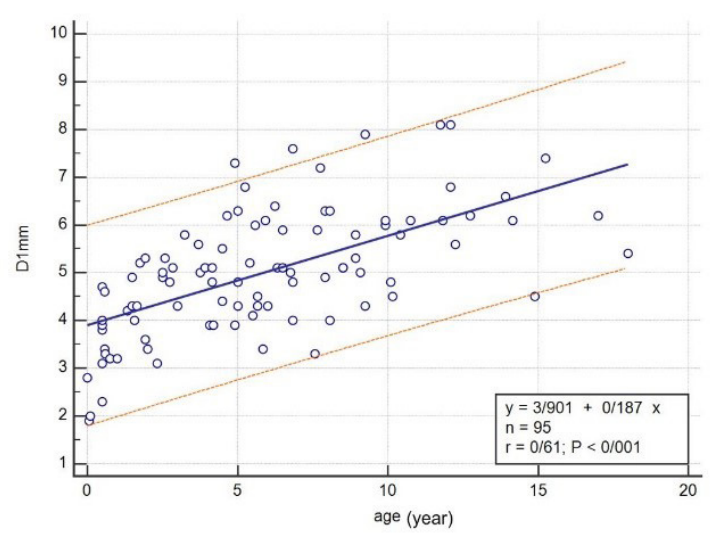

These data help physicians to diagnose some important CS disorders and also determine some CS normal variations.

CS is the main vein of the heart in almost all human beings; however, absence of CS in a few people is usually associated with other cardiac anomalies. ${ }^{13,14}$ Estimating the size of CS can be helpful in detection of some congenital heart diseases and decision making for some interventions. In this regard, a prospective study was conducted that evaluated CS anomalies in 204 patients and showed that the main anomalies were diverticulum of CS, presence of the left superior vena cava, and enlargement of the CS ostium. ${ }^{15}$

Zhang et al developed reference ranges for predicting the fetal CS mean diameter, and they showed significant differences between fetuses with and without persistent left superior vena cava. ${ }^{15}$

Many conditions cause CS dilation, such as right ventricle dysfunction, pulmonary hypertension, tricuspid stenosis, and regurgitation. A study showed the CS dilation in $81 \%$ of adults with pulmonary hypertension ${ }^{7}$. A similar study on children by Amoozgar et al showed dilation of CS in the pediatric age group. ${ }^{6}$

Moreover, some systemic and pulmonary venous anomalies may cause CS dilation, such as persistent left superior vena cava to $\mathrm{CS},{ }^{16}$ which is the most common thorax venous anomaly and causes dilated CS. ${ }^{8}$ Besides, in the partial or total anomalous pulmonary venous return,

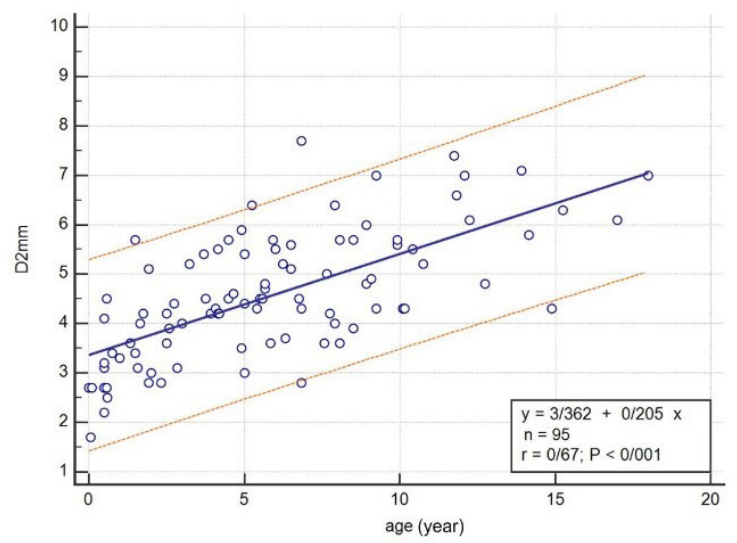

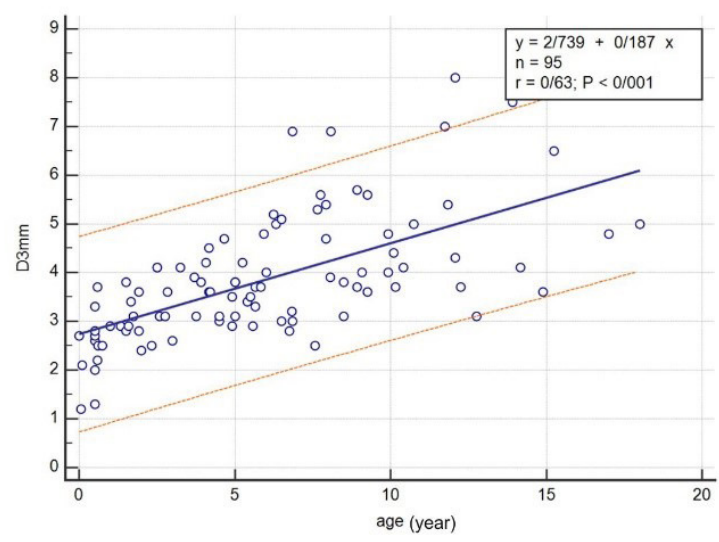

Figure 2. Linear Regression between Age and D1, D2 and D3. 

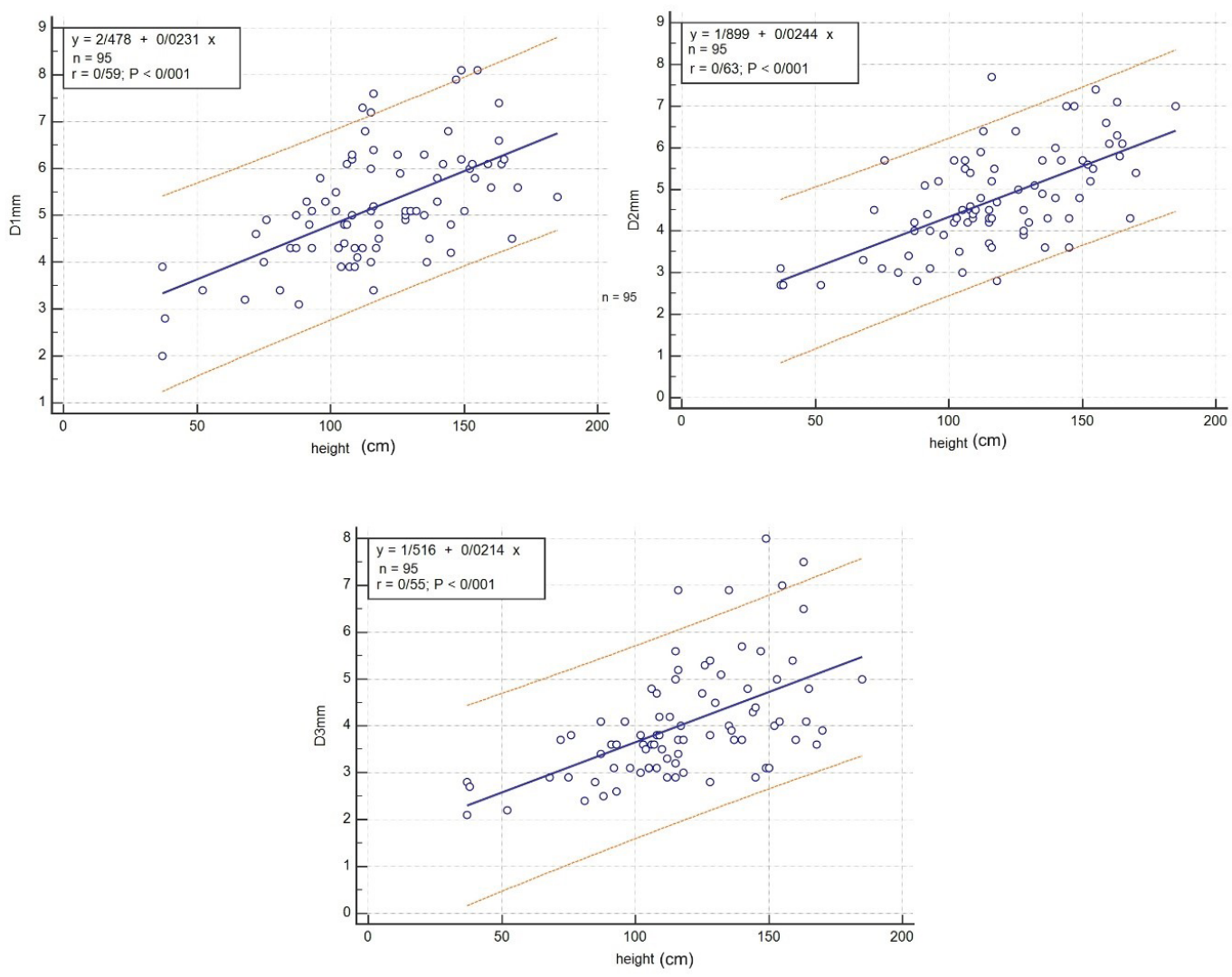

Figure 3. Linear Regression between Height, and D1, D2 and D3.
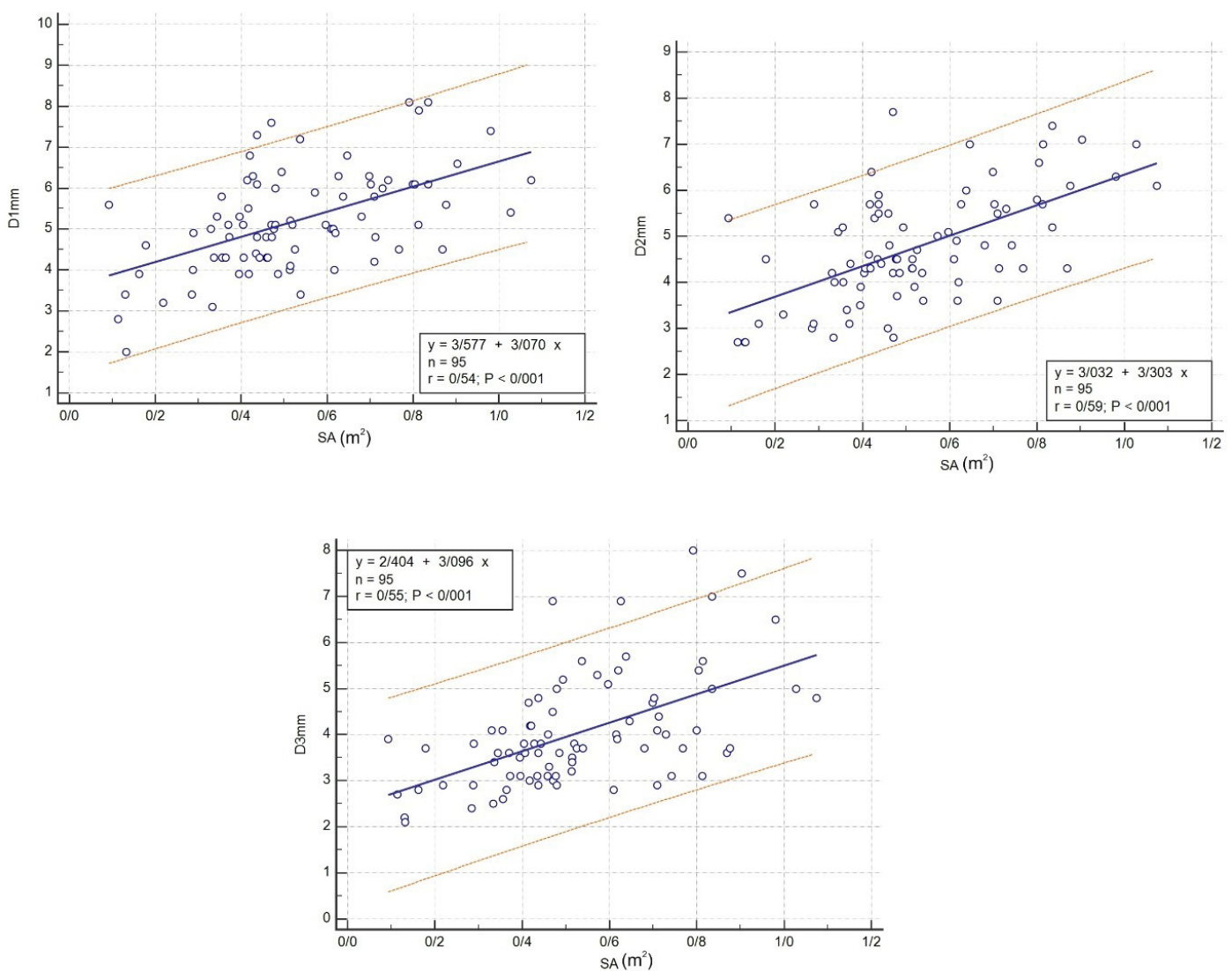

Figure 4. Linear Regression between Body Surface Area and D1, D2 and D3. 

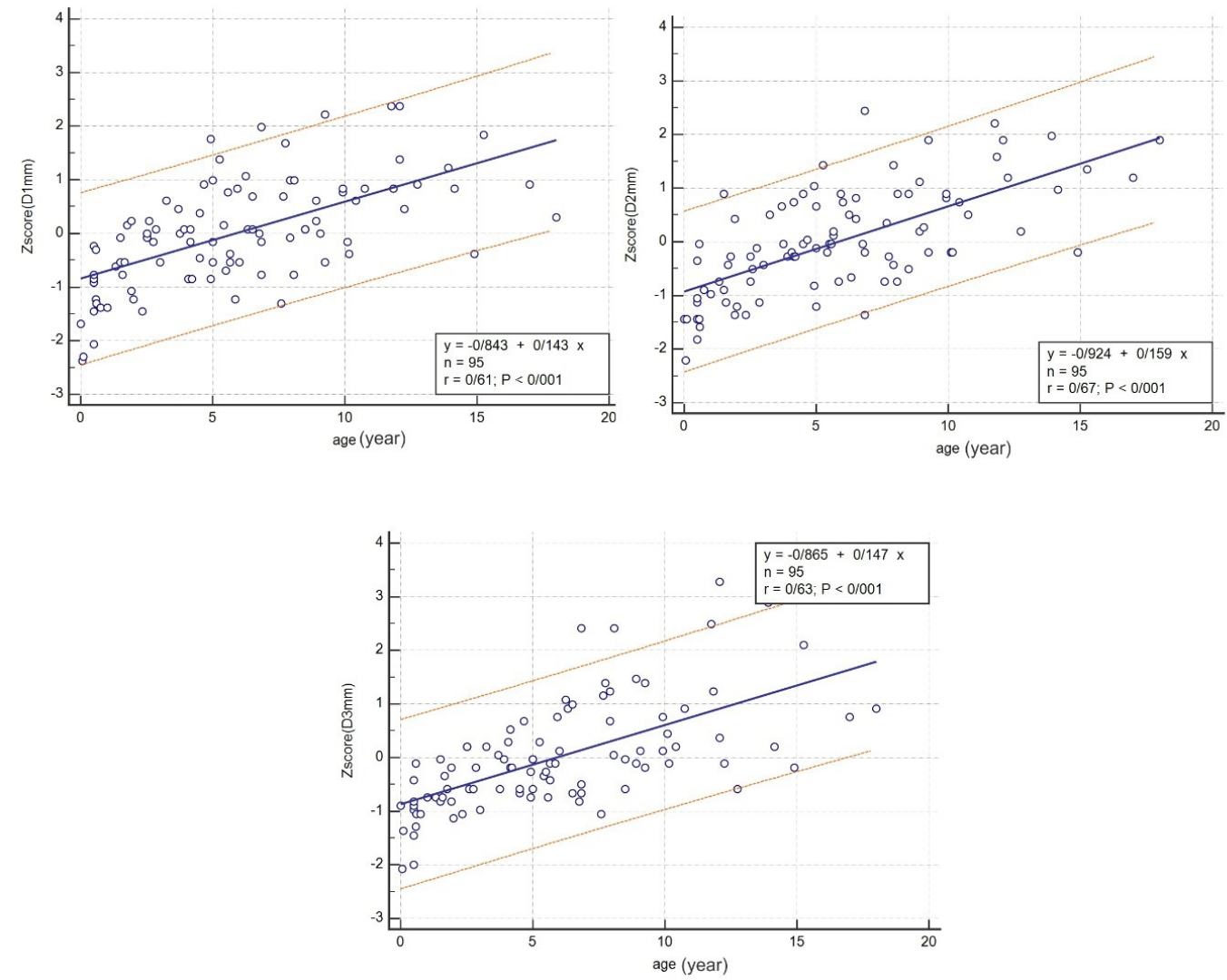

Figure 5. Linear Regression between Age and Z-scores of D1, D2, and D3.
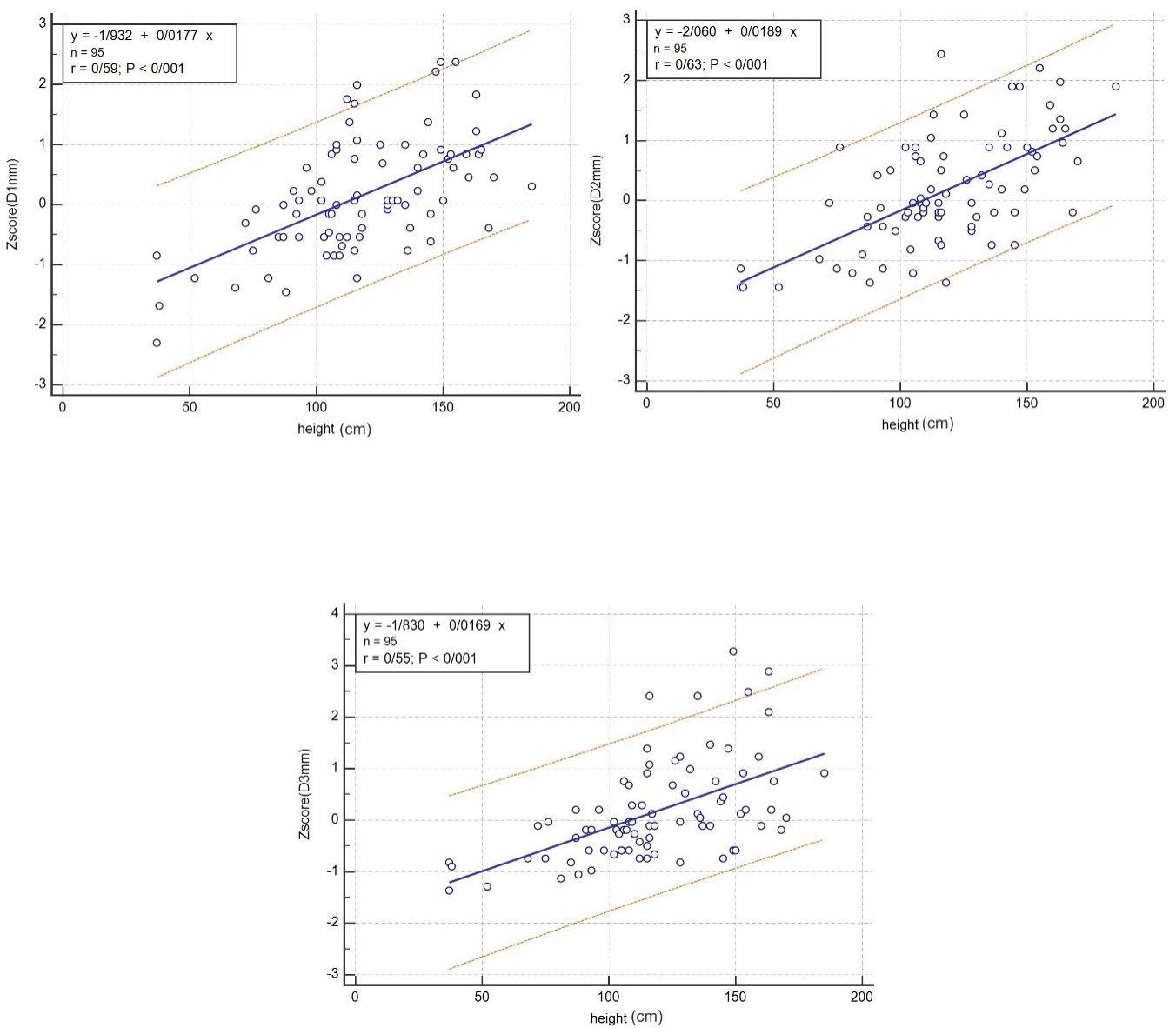

Figure 6. Linear Regression between Height and Z-scores of D1, D2, and D3. 

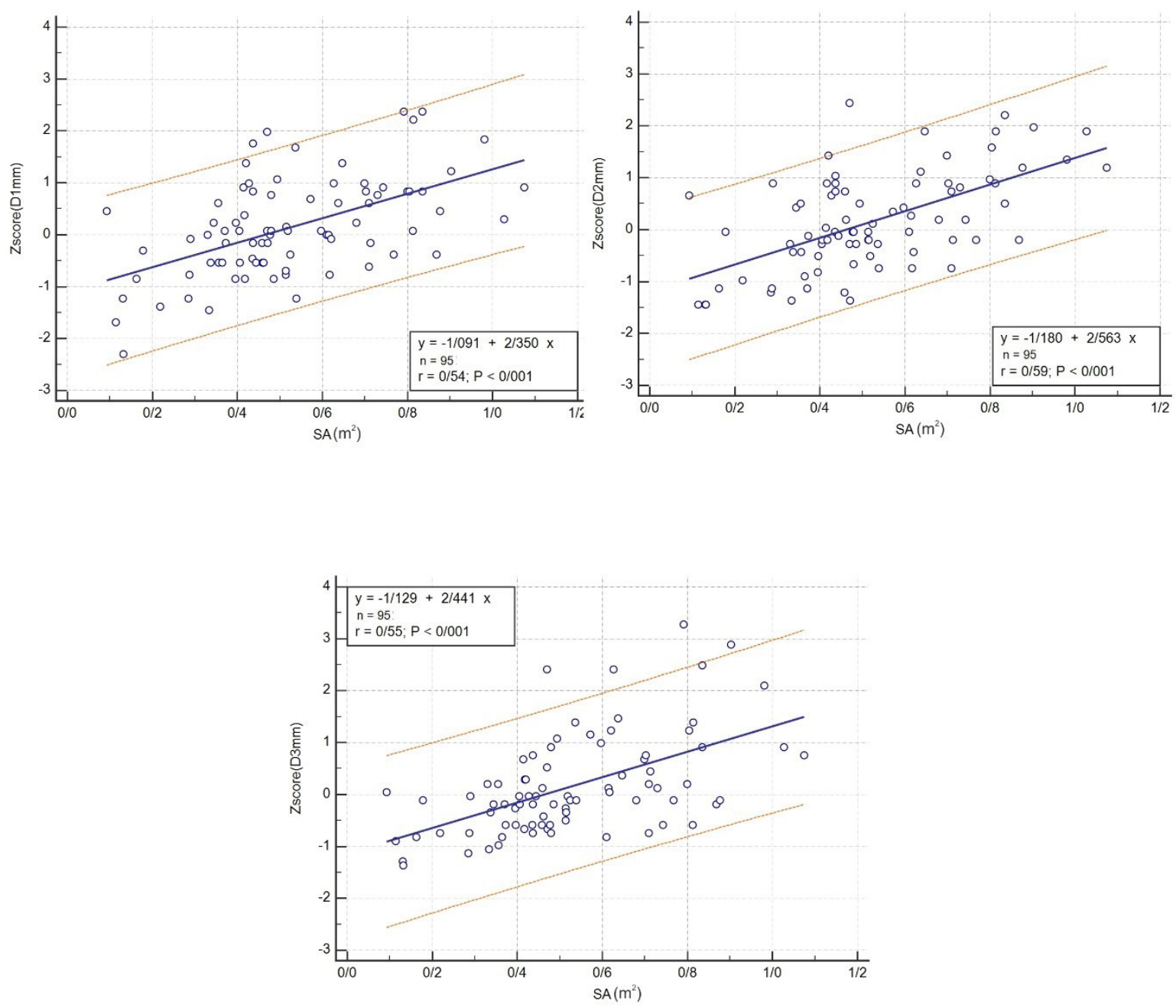

Figure 7. Linear Regression between Body Surface Area and Z-scores of D1, D2, and D3.

the pulmonary veins may drain directly into the CS or might connect to the thoracic veins such as persistent left superior vena cava and join the CS and result in dilated CS. ${ }^{17-19}$

Sometimes, the left superior vena cava can be joined to the left atrium in a syndrome described by Raghib in 1965, that presents with absent CS and a defect in the posteroinferior angle of the interatrial septum. ${ }^{18}$ The level of oxygen saturation decreases to $86-92 \%$ in this syndrome because of the right to left shunt and cyanosis complications, and brain abscesses might occur. ${ }^{13,18}$

This study will help clinicians to evaluate diseases that affect the CS diameter, such as persistent left superior vena cava connecting to the CS, anomalous pulmonary venous drainage, unroofed CS, pulmonary hypertension, and Raghib syndrome.

On the other hand, cardiac resynchronization therapy is an important remedy for adult patients with heart failure. In this procedure, knowledge of the CS size and position is essential for insertion of the device leads in the CS. Currently, percutaneous mitral valve annuloplasty has become feasible in adults utilizing a device placed in the normal CS. ${ }^{20,21}$

The cardiac CT scan and cardiac magnetic resonance imaging are suitable to identify CS anomalies. ${ }^{9,22,23}$ However, the gold standard for measuring the diameter of CS is cardiac catheterization and aortography, although there are many problems in using these methods, such as invasiveness and ethical issues.

Kronzon et al showed that transesophageal echocardiography is better than transthoracic echocardiography for measurement of CS. ${ }^{11}$ However, transesophageal echocardiography is more invasive than transthoracic echocardiography and is not suitable for routine cardiac evaluation. At the same time, the cardiologist must know the CS size while performing routine transthoracic echocardiography. In this study, we used transthoracic echocardiography to measure CS diameter at three sites. ${ }^{3}$

Ominde et al measured CS diameter in cadavers and showed that the CS diameter decreased from the proximal to the distal part. ${ }^{5}$ In our study, a decrease in diameter was also shown. Our study showed a significant correlation between the diameters of CS and the body surface area of individuals under 18 years of age.

In conclusion, we investigated the Z-score of the CS diameters among children and adolescents according to three different sites of CS length in 4-chamber view, and 
found a significant correlation between the diameter of CS and the children's age, height, and body surface area. This study reported the measurements of the CS diameters and their correlations in southern Iran. Performing this study in several regions of Iran will improve the validity of the findings among Iranian children.

\section{Availability of Data and Material}

All data are available and data sharing is applicable.

\section{Authors' Contribution}

HA: conception, design, final approval. VB: design and statistical management. ME: conception, design and statistical management. NM: revisions of the manuscript. HM: conception. AN: design. GA: echocardiography. PM: conception. ED: design. TH: conception. The authors read and accepted the manuscript.

\section{Conflict of Interest Disclosures}

None declared and the authors did not have any direct or indirect financial benefit for this study.

\section{Ethical Statement}

This study was approved by the Ethics Committees of Shiraz University of Medical Sciences, Shiraz, Iran (ethical code: IR.SUMS.med.rec1398.346). All procedures complied with the ethical standards of the related national guidelines on human experimentation of institutional and ethics committees, according to the Helsinki Declaration of 1975 and the revised version in 2008. The study was explained to all parents or guardians, and oral informed consent was taken.

\section{Funding}

There was no funder for our research.

\section{References}

1. Shah SS, Teague SD, Lu JC, Dorfman AL, Kazerooni EA, Agarwal PP. Imaging of the coronary sinus: normal anatomy and congenital abnormalities. Radiographics. 2012;32(4):9911008. doi: 10.1148/rg.324105220.

2. Loukas M, Bilinsky S, Bilinsky E, el-Sedfy A, Anderson RH. Cardiac veins: a review of the literature. Clin Anat. 2009;22(1):129-45. doi: 10.1002/ca.20745.

3. Młynarski R, Młynarska A, Gołba KS, Sosnowski M. Threedimensional visualisation of coronary sinus ostium from the inside right atrium perspective. Kardiol Pol. 2018;76(3):53641. doi: 10.5603/KP.a2017.0246.

4. Arunachalam K. Coronary sinus anatomy and its importanceevidence based review. Anat Physiol. 2016;6(2):1-3. doi: 10.4172/2161-0940.1000207.

5. Ominde BS, Odula P, Olabu BO, Ogeng'O JA. Regional differences in the diameter of coronary sinus among Black Kenyans. Anat Physiol. 2014;4(3):1-4. doi: 10.4172/21610940.1000141.

6. Amoozgar H, Fallahi M, Ajami G, Borzoee M. The relationship of coronary sinus dilation with pulmonary artery pressure in pediatric patients. Int Cardiovasc Res J. 2012;6(2):56-61.

7. Gunes Y, Guntekin U, Tuncer M, Kaya Y, Akyol A. Association of coronary sinus diameter with pulmonary hypertension. Echocardiography. 2008;25(9):935-40. doi: 10.1111/j.15408175.2008.00718.x.

8. Bolognesi M. Dilated coronary sinus due to persistent left superior vena cava in a healthy athlete: a case report with brief review. J Integr Cardiol. 2015;1(5):115-7. doi: 10.15761/

\section{jic.1000131.}

9. Genc B, Solak A, Sahin N, Gur S, Kalaycioglu S, Ozturk V. Assessment of the coronary venous system by using cardiac CT. Diagn Interv Radiol. 2013;19(4):286-93. doi: 10.5152/ dir.2013.012.

10. Malagò R, Pezzato A, Barbiani C, Sala G, Zamboni GA, Tavella $D$, et al. Non invasive cardiac vein mapping: role of multislice CT coronary angiography. Eur J Radiol. 2012;81(11):3262-9. doi: 10.1016/j.ejrad.2012.03.007.

11. Kronzon I, Tunick PA, Jortner R, Drenger B, Katz ES, Bernstein $\mathrm{N}$, et al. Echocardiographic evaluation of the coronary sinus. J Am Soc Echocardiogr. 1995;8(4):518-26. doi: 10.1016/s08947317(05)80340-2.

12. Song G, Liu J, Qiao W, Chen Y, Sun L, Ren W, et al. Regression equations of $Z$ score and echocardiographic nomograms for coronary sinus in healthy children. Int J Cardiovasc Imaging. 2016;32(12):1687-95. doi: 10.1007/s10554-016-0960-7.

13. Kong PK, Ahmad F. Unroofed coronary sinus and persistent left superior vena cava. Eur J Echocardiogr. 2007;8(5):398401. doi: 10.1016/j.euje.2006.06.004.

14. Foale RA, Baron DW, Rickards AF. Isolated congenital absence of coronary sinus. Br Heart J. 1979;42(3):355-8. doi: 10.1136/ hrt.42.3.355.

15. Zhang M, Li ZZ, Liu XP, Dong JZ, Ma CS. Coronary sinus: an important target of catheter ablation of atrialfibrillation. Chin Med J. 2009;122(23):2912-3. doi: 10.3760/cma.j.is sn.0366-6999.2009.23.021.

16. Alghamdi MH, Elfaki W, Al-Habshan F, Aljarallah AS. Bilateral superior vena cava with right superior vena cava draining into left atrium. J Saudi Heart Assoc. 2015;27(2):123-6. doi: 10.1016/j.jsha.2014.10.001.

17. Michalski B, Lipiec P, Chrzanowski $Ł$, Kasprzak JD. Giant coronary sinus secondary to partial anomalous pulmonary venous connection with combined mitral valve disease. Arch Med Sci. 2018;14(2):463-5. doi: 10.5114/aoms.2016.60100.

18. Raghib G, Ruttenberg HD, Anderson RC, Amplatz K, Adams $P$ Jr, Edwards JE. Termination of left superior vena cava in left atrium, atrial septal defect, and absence of coronary sinus: a developmental complex. Circulation. 1965;31:906-18. doi: 10.1161/01.cir.31.6.906.

19. Zhang Z, Zhang L, Xie F, Wang B, Sun Z, Kong S, et al. Echocardiographic diagnosis of anomalous pulmonary venous connections: experience of 84 cases from 1 medical center. Medicine (Baltimore). 2016;95(44):e5389. doi: 10.1097/ md.0000000000005389.

20. Sun C, Pan Y, Wang H, Li J, Nie P, Wang X, et al. Assessment of the coronary venous system using 256-slice computed tomography. PLoS One. 2014;9(8):e104246. doi: 10.1371/ journal.pone.0104246.

21. Catanzaro JN, Makaryus JN, Jadonath R, Makaryus AN. Planning and guidance of cardiac resynchronization therapylead implantation by evaluating coronary venous anatomy assessed with multidetector computed tomography. Clin Med Insights Cardiol. 2014;8(Suppl 4):43-50. doi: 10.4137/cmc. s18762.

22. Zhi AH, Dai RP, Ma WG, Zhang P, Lv B, Jiang SL. CT angiography for diagnosis and subcategorization of unroofed coronary sinus syndrome. J Thorac Dis. 2017;9(10):3946-55. doi: 10.21037/jtd.2017.09.03.

23. Abbara S, Cury RC, Nieman K, Reddy V, Moselewski F, Schmidt $S$, et al. Noninvasive evaluation of cardiac veins with 16MDCT angiography. AJR Am J Roentgenol. 2005;185(4):10016. doi: 10.2214/ajr.04.1382. 